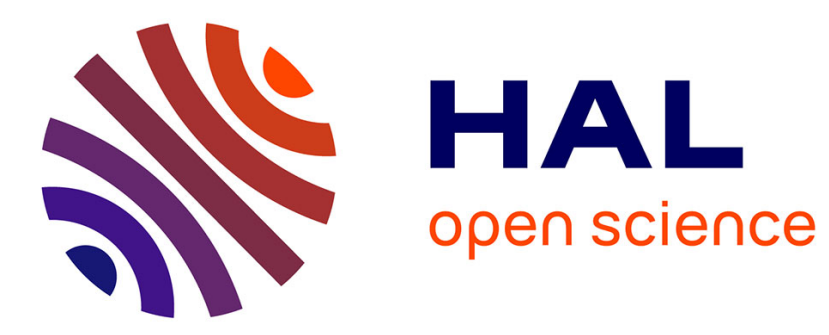

\title{
Inequality in Knowledge Production: The Integration of Academic Infrastructure by Big Publishers
}

\author{
Alejandro Posada, George Chen
}

\section{To cite this version:}

Alejandro Posada, George Chen. Inequality in Knowledge Production: The Integration of Academic Infrastructure by Big Publishers. ELPUB 2018, Jun 2018, Toronto, Canada. 10.4000/proceedings.elpub.2018.30 . hal-01816707

\section{HAL Id: hal-01816707 https://hal.science/hal-01816707}

Submitted on 15 Jun 2018

HAL is a multi-disciplinary open access archive for the deposit and dissemination of scientific research documents, whether they are published or not. The documents may come from teaching and research institutions in France or abroad, or from public or private research centers.
L'archive ouverte pluridisciplinaire HAL, est destinée au dépôt et à la diffusion de documents scientifiques de niveau recherche, publiés ou non, émanant des établissements d'enseignement et de recherche français ou étrangers, des laboratoires publics ou privés. 


\title{
Inequality in Knowledge Production: The Integration of Academic Infrastructure by Big Publishers
}

\author{
Alejandro Posada and George Chen
}

\section{EDITOR'S NOTE}

Both authors are equal contributors

\section{Introduction}

1 As major academic publishers' have redirected their business strategies to open access and alternative paying structures, it could be argued that this represents a move towards more democratic access to knowledge. However, this paper problematizes this claim by documenting and examining what has been a simultaneous redirection of big publishers' business strategy towards the acquisition and integration of scholarly infrastructure, the tools and services that underpin the scholarly research life cycle, many of which are geared towards data analytics. We argue that moves toward openness and increased control of scholarly infrastructure are simultaneous processes of rent-seeking which could further entrench publishers' power and exacerbate the vulnerability of already marginalized researchers and institutions.

2 This paper's primary objective is to systematically document economic concentration in the academic publishing industry in order to situate recent shifts towards the acquisition of scholarly infrastructures and evaluate its implications for inequality in knowledge production. We hypothesize that recent shifts have been possible because of an already disproportionate publisher ownership of academic content and that the implications 
include increased dependence by researchers and institutions as well as the construction of an unequal scholarly communications landscape making it harder for alternative services and products to succeed in the industry. The paper proposes to examine this claim by undertaking an empirical case study of the mergers and acquisitions of three of the five major academic publishing companies (RELX-Elsevier, John Wiley \& Sons-Wiley Blackwell, Informa-Taylor Francis). The study focuses primarily on the case of Elsevier and Wiley as the companies present a longer history of transitioning towards infrastructure and data analytics.

\section{Conceptual Framework}

3 This paper builds upon previous work which has empirically documented and questioned the oligopolistic tendencies within the academic publishing industry following the digital turn (Lariviere 2015). The work of Lariviere et al. presents an increasingly disproportionate ownership of academic journals and papers in natural and the social sciences by the top 5 academic publishers (Elsevier, Wiley-Blackwell, Springer, and Taylor Francis and Sage). Their findings suggest that the top five publishers accounted for more than $50 \%$ of all papers published in 2013 (Lariviere et al. 2015). We build upon their findings by documenting a simultaneous process of concentration of scholarly infrastructure within academic publishing and higher education and analyzing its contribution to the oligopolistic tendencies in the industry. We propose that the process of concentration of content and infrastructure in academic publishing are inherently interconnected and that as such they should be analyzed together when looking at consolidations of big publishers' control and their move towards open access. The analysis follows a political economy theoretical framework and relies on the conceptual frameworks of rent-seeking, and value grabbing in its analysis of the evolving business strategy of big academic publishers.

These analytical tools facilitate a deeper understanding of how rent relations are asserted and maintained and its implications to inequality in scholarly communications. The relevance of rentiership theory to the political economy study of the STS field has been outlined by Birch's work (2017). Rent relations are social relations of value distribution that the owner of an asset has as a result of the ownership of the asset rather than of its production (Andreucci 2017), while value grabbing is defined as the appropriation of surplus value through rent relations (ibid.). The costs of production of academic journals drastically decreased as a result of the digital era, theoretically making knowledge more accessible but also threatening the profits of the publishing industry. However, rentseeking theory explains why the turn of the digital era allowed the publishers to establish themselves as a rentier class that freely acquires academic papers as intellectual property assets and then captures rent through their entitlement. Club goods theory provides a framework through which to understand how knowledge in the form of academic papers in the digital era was converted into goods which are non-rival, such that the consumption of the good by one does not impede the consumption by another, yet excludable, such that one may be excluded from its consumption (Schwartz 2017). These theoretical frameworks help explain how the active concentration of academic content and the oligopolistic behaviors in the academic publishing industry have been an intrinsic component in the establishment of academic papers as club goods and the establishment of their entitlement for the continual appropriation of surplus value. 
Furthermore, we propose that rent-seeking theory also elucidates how the simultaneous move towards controlling the infrastructure around the education and publishing lifecycle further exacerbates publishers power and control deepening their ability of extracting surplus profits.

\section{Methodologies and Materials}

5 We documented the economic concentration of major academic publishers over the past 20 years using Factset and Capital IQ3 to extract financial data such as Merger and Acquisition (M\&A) and revenues. We also collected data on publishers current service offerings as presented on their website and on financial reports. Here, data has been aggregated into tables sorted by date consisting of over 340 M\&A for Elsevier, 80 for Wiley and over 240 for Informa (Taylor \& Francis). The items have been categorized between academic content and academic services/data analytics. The analysis will look at the extent to which publishers have extended beyond the traditional roles of academic publishing into associated processes throughout the knowledge production cycle. This will include a systematic analysis of the various companies/services acquired or launched by these publishers. The analysis will focus on the implications of what could be considered a vertical integration of scholarly infrastructure by major publishing corporations. At this point, we have not included Springer and Sage into our analysis because they are private companies and thus data on their M\&A is not disclosed on financial databases. We recommend further research on their activities, perhaps using different methodology.

\section{Key Findings on Merger \& Acqusitions of Academic Publishers}

6 The tables below present our findings for the M\&As of Wiley, Elsevier, and Taylor \& Francis. The tables showcase the relationship between a historic process of acquiring academic content and that of acquiring scholarly infrastructure and services.

Figure 1: Elsevier Mergers and Caps Product Launches




Figure 2: Wiley Mergers and Product Launches



Figure 3: Taylor \& Francis Mergers and Product Launches

\section{Count of Count}

Taylor Francis Mergers and Acquisitions

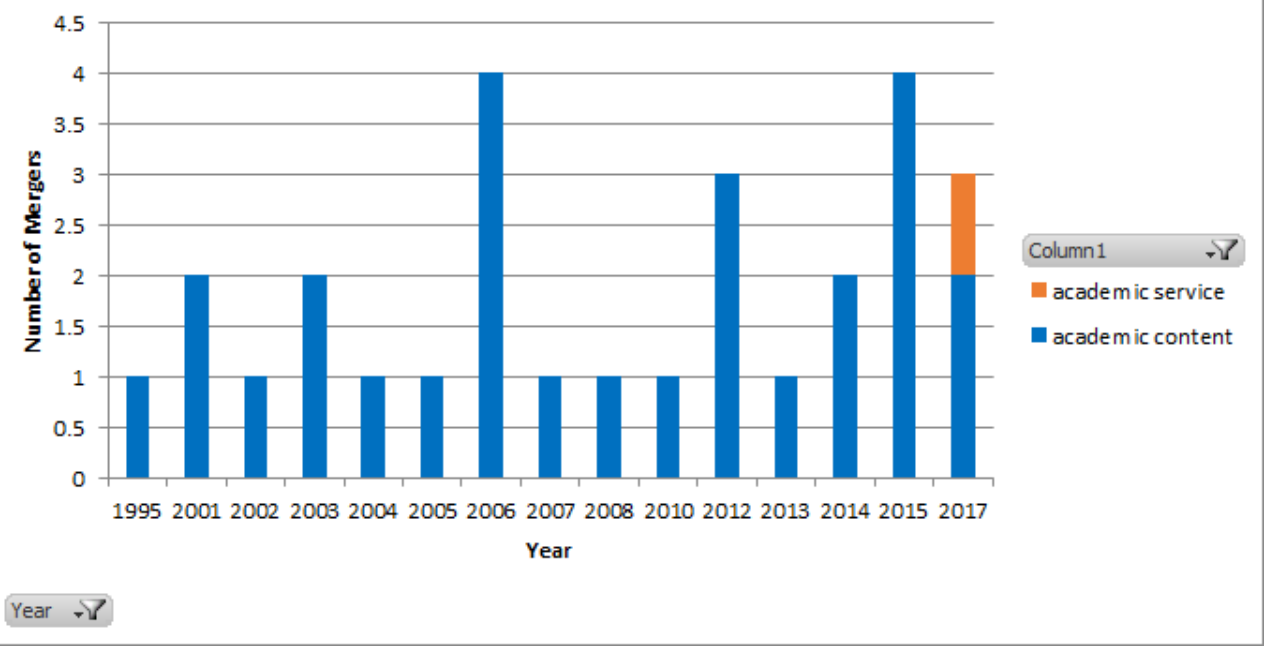

7 As expected, the tables show that all three companies have had a historical increase in concentration through the merger and acquisition of academic content. The findings corroborate claims of the disproportionate and continued concentration of academic content and its implications to the oligopolistic tendencies in the industry (Lariviere et al. 2015). Taylor \& Francis are exemplary of this argued trend as demonstrated through their increasing acquisitions of content from 2013 to 2015. Beyond the expected concentration of academic content, the findings also brought to light an increasing interest in the acquisition of academic services and data analytics primarily since 2007-2008 and by Elsevier and Wiley. A scan of press releases over the past 4 years showed that Taylor and Francis could also be starting to head in a similar direction.

The remainder of the paper analyzes the potential motivations and implications following the rising trend by large publishers towards the acquisition of services and data analytics 
as documented by our findings. The subsequent analysis focuses primarily on the experience of RELX and Wiley since their transition towards the acquisition of services is relatively well established and thus facilitates an analysis of potential implications for the entire industry as well as knowledge production at large. A preliminary analysis of how Taylor and Francis could be heading in the same direction is also presented. We will first showcase the extent of the transition towards the acquisition of infrastructure before discussing the economic context under which the transition is taking place and the potential motivations and implications of such a transition.

\section{Vertical Integration of Publishers}

The following section expands on the case of both Elsevier and Wiley with the purpose of conceptualizing what a transition towards the acquisition of infrastructure and data analytics actually entails. Our data suggest that the purchases and service launches of Elsevier primarily relate to the academic knowledge production process, a process involved in the creation and production of academic journals; while Wiley's purchases and service launches relate to the education value chain, a process related to university education.

The next diagram expands on the analysis of Elsevier to look into how the acquisition of academic services appears across the academic knowledge production life cycle. This analysis requires an understanding of the various stages involved in the knowledge production process. Figure 4 presents a simplified depiction of the various stages involved in the academic knowledge production process. We divided this into three connected sections; the research process, the publishing process, and the research evaluation process. Elsevier academic services were examined individually to see what part of the knowledge production cycle they were targeting. Figure 5 depicts the results. The findings showcase the extent of Elsevier expansion through its acquisitions of various key infrastructural components a phenomenon that we analyze as a vertical integration of the academic production value chain. 
Figure 4: The Academic Knowledge Production Lifecycle



Figure 5: Elsevier Presence Throughout the Lifecycle

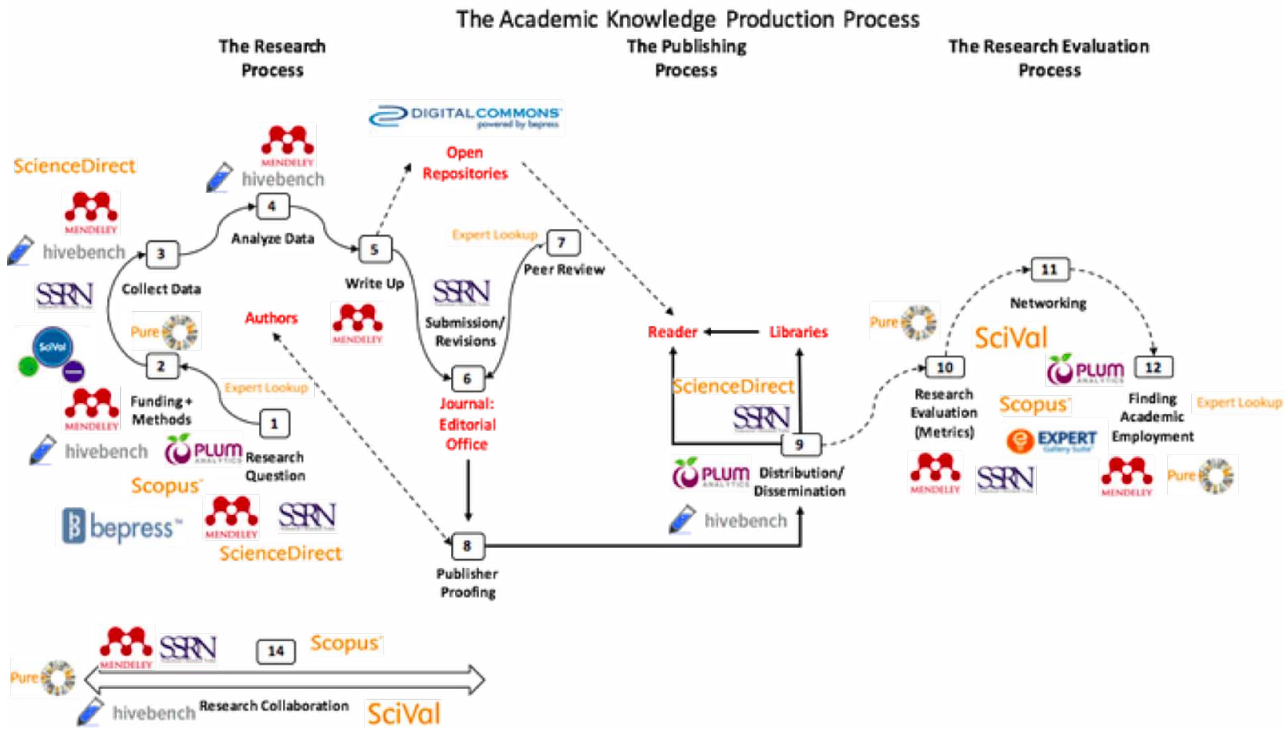

11 Elsevier has acquired and launched products that extend its influence and its ownership of the infrastructure to all stages of the academic knowledge production process, for which there is a parallel in Wiley with regards to the education value chain.

12 To situate the acquisitions of Wiley in a similar lifecycle, and to visualize Wiley's acquisitions of and product launches within the education sector, an understanding of the higher-level education cycle is similarly needed. Figure 6 showcases a simplified depiction of the various stages involved in the university education process. We have color-coded the stages into 3 primary types: blue-for the primary university education process, green-for the student oriented activities such as recruitment and retention which are vital to the continued function of the process, and orange-for post-university 
education. Wiley services were examined individually to see which sections of the education cycle they were targeting. Figure 7 depicts the results.

Figure 6: The Education Lifecycle

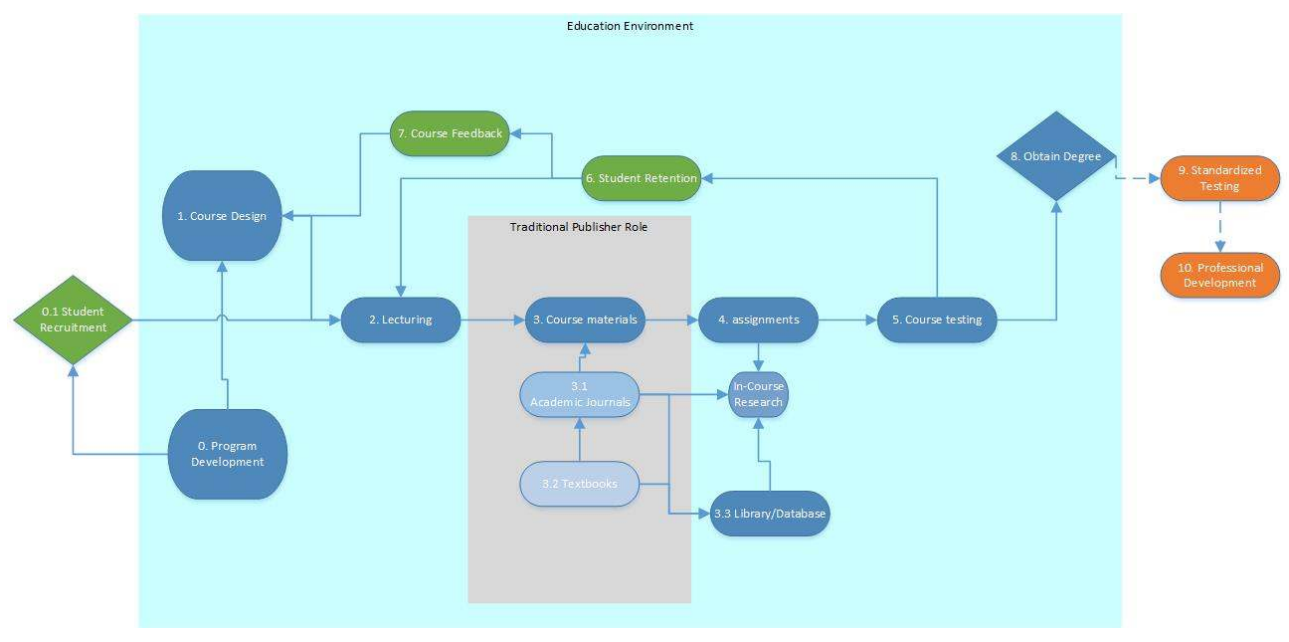

Figure 7: Wiley Presence Throughout the Lifecycle



As hypothesized Wiley showcases a similar vertical integration within the education life cycle due to its acquisitions and product launches. Wiley's strategy similarly attempts to enhance its control in the education process, especially, within online education.

Some have championed this phenomenon under the idea that vertical integration of the value chain allows for efficiency and better-integrated services and products (Schonfeld 2017). However, it is precisely because of the power to integrate products across the value chain that this expansion should be critically examined. While we acknowledge the many benefits of a better integration of academic services we problematize the implications of the fact that this integration is occurring under the control of large corporations with allegations of oligopolistic behaviors. Specifically, the vertical integration increases dependence by consumers (universities, lecturers \& researchers) on Elsevier and Wiley, as well as transforms the institutional/individual decision-making process, ceding increasing control to the two. In both cases, a large proportion of the dependence is generated through the integration of services which given the disproportionate ownership of content makes it harder for institutions and individuals within the 
education and research community to exist outside the vertical integration generated by the companies. Beyond this dependence through convenience, however, Elsevier attempts enhance its "vitalness" as the source of decision making data; while Wiley places primacy upon online courses, for which the expertise and infrastructure of it and its rivals are similarly "vital" to effective performance.

It is important to note that certain partners with Taylor \& Francis such as Altmetric (2015), while independently launched, were purchased by other major publishers (Digital Science 2012), with Taylor \& Francis thus contributing to the increasing consolidation of control and validation of the knowledge production process. In fact, Taylor Francis' purchase of Colwiz, an academic infrastructure product with features similar to Mendeley, in 2017 may represent the beginnings of a more aggressive trend towards the acquisition of scholarly infrastructure by this player as well (Taylor \& Francis 2017). The following sections expand upon the economic context under which the transitions are taking place as well as the potential motivations and implications of such a transition.

\section{Digital Era, Open Access, and Publishers Profit}

16 The following section focuses on the historical profit margins of both Elsevier and Wiley so as to contextualize the effects that the turn of the digital era, the rise of open access and the recent transition towards infrastructure and data analytics have had on the profitability of this companies. The purpose is to showcase how the transition towards the acquisition of infrastructure represents part of a rent-seeking strategy by the companies. Figure 8 and figure 9 present the profit margins from the 1990s to 2015 for Elsevier and Wiley respectively. 


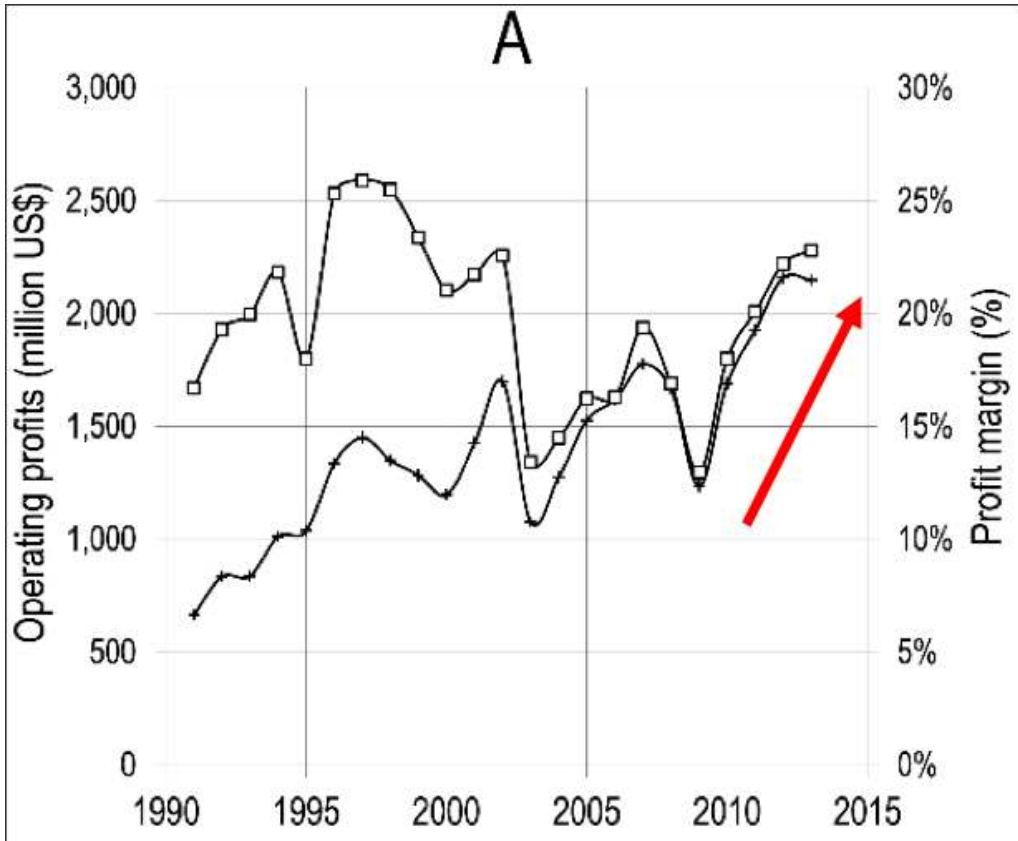

$\square$ Profit margin + Operating profits

(Lariviere et al. 2015)

Figure 9: Wiley Profitability



17 Historical profit margin of these two major publishers shows how they were able to sub come and to a certain extent maintain their margins despite the predicted collapse of the industry as a result of the rise of the digital era at the turn of the century. In large, the ability to maintain their power as a result of the active production of the highly controversial and artificial paywall and the resulting construction of academic knowledge as a club good. However, the profit margins also show that the companies have not been necessarily affected by the rise of open access and in fact have seen either stable or rising 
profit margins. In fact, this companies have come to embrace certain models of open access and have become key players in the open access agenda despite the apparent threat it poses to their profit models. It is interesting that such embrace has occurred alongside a purposeful rebranding of the companies as information analytics. It is in the context of open access and stable profit margins that we situate the vertical integration and concentration of scholarly infrastructure by large academic publishers. We argue that the simultaneous investment into infrastructure and embrace of open access has been driving the rent-seeking agenda of the publishers with dire consequences to the diversity of knowledge production.

Wiley's annual shareholders' updates have described "Solutions business", Wiley's academic services branch, as a key contributor to recent profitability (John Wiley and Sons 2017). The relation between profitability and the move towards services and analytics has also been made apparent in the explicit rebranding of the companies as well as press statements by high-level employees. Here, a quote of RELX's strategic direction from its 2007 annual report may illuminate the situation:

Leverage our leadership brands and authoritative proprietary content to deliver innovative, solutions-orientated products that become embedded in customers' workflows and enable Reed Elsevier to move up the value chain. (RELX 2008)

In fact, figure 8 presents a rise in profit margins after 2010 which is also the time when Elsevier started moving into the acquisition of infrastructure more aggressively according to figure 1 . Not only does the shift into academic services and data analytics enable companies to diversify their income streams through new modes of monetizing content ownership, but RELX has clearly described the strategic intent to consolidate dependence on their own services, ensuring continuous consumption of their products. It is such a strategy which directs the generation of decision-assisting data/information analytics as well as the promotion of impact metrics by RELX. We will further analyze the implications of this workflow embedment.

While less explicitly worded, Wiley has described a similar intent to diversify in its 2011 annual report:

The company believes that the demand for new electronic technology products will continue to increase. Accordingly... the Company has increased its expenditures related to such new technologies and anticipates it will continue to do so for the foreseeable future. (Wiley 2011)

This intent has been made far more explicit in the latest 2017 annual report:

"The Company continues to transform its business from a traditional publishing model to being a global provider of content-enabled solutions with a focus on digital products and services." (Wiley 2017).

It is thus clear that the transformation from the traditional role of publishers to solutions providers has become the strategic goal of both companies, a reflection of the benefits and potential profitability of the solutions providing model to publishers.

We have simultaneously noted the correlation of mergers and acquisitions with increased profitability. Yet it is important to note given the diversification into academic services/ data analytics that the target of expansion paths is distinct. RELX, in particular, has targeted the knowledge production cycle as its expansion path while Wiley has chosen to differentiate itself through the targeting of the education process (see below). This strategy may be a form of oligopolistic activity as the diversification of expansion paths allows for the greater application of monopoly power by each firm. There still exists 
competition within the markets, however, as Springer has made similar acquisitions towards data analytics and companies within the knowledge production life cycle (Digital Science 2018). While we will analyze the implications of Elsevier's and Wiley's expansion below, we recommend further research into the implications of Springer's expansion and SAGE, if any.

\section{Analysis} place, we will next describe the implications of the vertical integration of academic services. Here, we will examine implications at the individual as well as the institutional level. In both cases, a dependency towards the publisher's product lines is generated, with this dependency then enhancing the influence and control of publishers at the individual and institutional level. We will then expand the implicational analysis and attempt to extract insight through a rentiership framework, before discussing the potential for exclusion towards global south researchers.

\section{Dependency at the Individual Level}

At the individual level, both Elsevier's and Wiley's products are used due to convenience and generate dependency to the entire product suites through their forward and backward integration with other in-house products. With Elsevier, Mendeley's Reference Manager (Mendeley 2017a) and Hivebench's lab notes (Elsevier 2018a) features encourage the use of other Elsevier products for which there is integration. In parallel, Wiley's offering of Course Workflow services such as WileyPLUS, provides online testing and is integrated with Wiley's textbooks through the features of online tutorials (John Wiley \& Sons 2018a), reducing the need for lecturers, the individuals within the education process, to develop questions and enhancing dependency. Here, Wiley further provides features such as Custom Select (John Wiley \& Sons 2018b) which simplifies the content selection process within the Wiley content ecosystem, further enhancing dependency. Yet Elsevier goes beyond Wiley in generating dependency. An increasing dependency on DOI is formed for Mendeley users with the convenience of automatic DOI generation (Mendeley 2017b). Beyond merely encouraging the use of the suite, products such as Mendeley (Mendeley 2017c) and SSRN (SSRN n.d.a) further promotes collaboration with other researchers on the platform, entrenching dependency by serving as the infrastructural basis for collaborative communication. It is through the individual entrenchment within the Elsevier Suite, despite the freenium nature of services such as 
Mendeley (Mendeley 2017d) and SSRN (SSRN n.d.b), that Elsevier may further extract value from the remainder of its services. While for Wiley, the conveniences of WileyPLUS, and its associated savings at the university level encourage dependency, an increasing reliance on the product due to its lower cost relative to activities such as the hiring of Teaching Assistants for assignment grading. This allows for the further extraction of value in terms of sums the university would have paid to other parties.

With Elsevier in particular, It is here that the increased dependency strengthens monopoly power and facilitates the exacerbation of rent-seeking behavior, in addition to ensuring the continued demand for and supply of their academic content especially with the advent of Open Access.

\section{Influencing Individual Decision making}

The dependence encouraged upon users through the integration of services can have direct consequences on the decision making of individual researchers/lecturers and academic institutions. Here the careers posting and funding database within Mendeley (2017e and 2017f) may influence researcher applications for specific grants, while Wiley possesses a parallel in their Wiley Job Network (John Wiley \& Sons 2018c). The individual influence exerted by Elsevier and Wiley differ however in their mode of action.

With Elsevier, SSRN's rankings for journals (SSRN n.d.c) and curated ejournal (SSRN n.d.d) may further influence the direction of research for individuals merely through visibility. Yet it is SciVal Funding which has the greatest influence on researchers through its ability to recommend targeted funding opportunities for researchers as well as potential collaborators to enhance the possibility for maximum finding (Elsevier 2018c). Similarly, Elsevier Journal Finder (Elsevier 2018d), using Elsevier Fingerprint Engine (Elsevier 2018e), recommends the most suitable journals for work publication, journals with the greatest opportunities for success. While services may be used individually, the crossservice integration of Elsevier services encourages the collective use of services due to additional convenience, thereby maximizing Elsevier's influence at the individual level.

In Wiley, the convenience of its ecosystem may reduce the willingness of lecturers to leave it, potentially leading to certain topic compromises. Additionally, individuals are influenced by institutions to alter the structure of courses in incorporate technology such as WileyPLUS due to the potential course savings with the reduction in Teaching Assistants needed, in grading or teaching. Furthermore, End-to-End online degree consulting and management services such as Wiley Education Services (acquired as Deltek) has Wiley consult at the course level (Wiley Education Services 2018). Here, Melbourne Business School, the business school of an Australian public research university, serves as an example of the increasing influence of Wiley within the academic education process, as Wiley has been hired to: Incorporate digital technology into the learning process... The transformed subjects will have a more individualized, studentcentric learning process to improve student learning outcomes and be more efficient for both students and faculty. (Wiley Education Services 2017)

31 Here, control in the hands of the individual lecturer is further reduced with the top-down instituted Wiley consulting, with Wiley gaining additional influence over the learning process. 
32 In both Elsevier and Wiley, institutions and individuals are encouraged to adopt the services due to inter-institution competition. In Elsevier, funding competition and the need for publication success drives this adoption, while in Wiley, cost reductions and competition between institutions for students serve as the rationale for this adoption. Yet in both cases, control is transferred to the publisher as their recommendations/ consulting becomes increasingly "crucial" to achieving the goals of institutions/ individuals, whether funding/publication or enhanced enrollment in education; with the motivations of the institutions in particular tied into the global university rankings. At the same time the integration of services by large publishers and the resulting dependence makes it harder for alternative services to emerge or succeed, particularly since they do not have the disproportionate access to content which can be used to reduce service operating costs in addition to being integrated into their service. The vertical integration is affecting individual decision making not only as a result of convenience but also as a result of the increasing progression towards a lack of choice especially as the convenience of the services and their increasing user base makes the use of such services increasingly mandatory. As such our paper shows that the decision to boycott large publishers is much more complex than the decision not to publish in the journals they own. It is a decision to be outside the integrated academic knowledge infrastructure that they have acquired and as such it has direct implications to researchers ability to find jobs, or access to funding and to collaborate with other researchers. Through their rebranding of information analytics, Elsevier and Wiley have used these technologies to produce and reproduce systems of dependence.

\section{Transforming Institution Management: Dependency via workflow embedment}

33 The source of inter-university competition, whether in research or education, as an incentive to adopting Elsevier/Wiley products is far greater at the institutional level. Here, Elsevier has acquired products such as Bepress (Bepress 2017a), Pure (Elsevier 2018f), Plum (Plum Analytics 2018), and SciVal Funding (Elsevier 2018c) to optimize the university workflow, while Wiley offers an end-to-end service in the specific field of online degree education (Wiley Education Services 2018). Pure embeds Elsevier within the university workflow process through its abilities to manage research at the university level, including the provision of a dashboard to facilitate decision making (Elsevier 2018f). Able to generate targeted funding recommendations using the Elsevier Fingerprint engine, Pure enables a top-down flow of recommendations, and thus control, with Elsevier through Pure recommending to institutions. Bepress further offers a complete institutional repository with infrastructure support on open education as well as workflows for Thesis and Dissertation (Bepress 2017a). Here, Digital Commons entrenches the university dependence on Elsevier for publication, while offering workflow management for Thesis and Dissertations to enhance dependency. Simultaneously, Bepress has Expert Gallery Suite which attempts to raise the visibility of university researchers by showcasing access and use of their research, in addition to publication performance (Bepress 2017b). Bepress further attempts to optimize institutional output by moving academic output to the top/near-top of search results (Bepress 2017c). This places universities into greater dependency upon Bepress or its competitors as institutions increasingly optimize their research visibility. 

programs through the offering of an end-to-end online degree consulting and management system (Wiley Education Services 2018). Beginning in the program design stage, where market-oriented strategy is offered, and culminating in education and testing on their in-house Learning Management System (ibid.), Wiley attempts to enhance its control of the online education infrastructure. Here, the competitiveness of an university's online programs are enhanced, with the expertise/infrastructure of Wiley, while dependency is raised in the use of such expertise/infrastructure. Ultimately, control is ceded in the online education process towards the developers of the infrastructures and the recommendations of the experts, Wiley. As such, through institutional attempts at enhancing competitiveness, whether in research or education, institutions become further dependent on the products of Wiley and Elsevier.

\section{Influencing University Strategy}

vertical integration of both firms have the effect of influencing university decision making, with the adoption of Elsevier products, especially Bepress, Pure, Plum, SciVal influencing university decision making through their promotion of data analytics and with Wiley, direct attempts to influence through market based consulting.

With Elsevier, Pure offers a dashboard as well as other statistics for universities to base their decision making (Elsevier 2018f), while Plum offers an entire suite of data analytics (Plum Analytics 2018). Bepress promotes the use of "Impact Analytics" for universities to engage in trends and tap into collaborative opportunities in addition to the use of Data Analytics as a method of showcasing the "vitalness" of work (Bepress 2017d). Promoting the use of metrics in the decision making process under the promises of efficiency (Elsevier 2018f), Elsevier, as the generator of data analytics, entrenches itself in the process of university decision making. Yet Elsevier further serves to influence university decision making by acting as the creator of source data through its algorithms. Here, in adopting Elsevier products, universities simultaneously cede a portion of their control to Elsevier. For the source of their decisions are no longer the publications and actions themselves, but statistics processed and provided by Elsevier, a clear conflict of interest due to else of the proprietary algorithms used in the generation of not only statistical data but also in recommendations pushed by its software. In this sense, SciVal further encourages the publisher influenced modality of decision making, by offering the ability of utilizing metrics to compare performance between universities as well as recommending potential collaboration partners at the university and individual level (Elsevier 2018g). Decisions made as such are fundamentally influenced by Elsevier through the use of metrics created by Elsevier. The epitome of Elsevier's attempts to influence university decision making comes through Elsevier Analytical Services, whereby Elsevier's in-house team provides a report of the university's performance amongst its peers (Elsevier 2018h). Here, Elsevier describes to the university the university's performance and makes the corresponding recommendations, cementing their influence in university decision making.

While Wiley attempts to influence education strategy directly with its consulting, describing their services as market demand based analysis (Wiley Education Services 2018). Here, although Wiley may provide the existing experience in online education, the focus of market demand in program development may lead to a focus on "hot" programs, 
with Wiley explicitly releasing an article on the viability of online MBA programs (Wiley Education Services 2017). Thus Wiley's influence extends beyond merely the integration and alteration of existing programs but rather attempts to encourage an explicit direction in the strategic path of the university, here in the direction of online MBAs for schools with business school programs. There is thus a clear attempt by Wiley to enhance its control over the university decision making process in education, as Elsevier has for Academic Knowledge Production.

With the various product offerings in the Academic Production Cycle, Elsevier entrenches dependence upon its products and enhances its influence in institutions as paralleled by Wiley's activities within the Education Value Chain. Yet despite the parallels in their behavior, the key separation of strategic direction clearly represents an additional feature within Oligopolies, with the differentiation of expansion fields being a method of avoiding direct competition. Yet the final objective of both companies is the same, being the use of such vertical-integration to extract additional value. With Elsevier in particular, said activity is a form of rent-seeking simultaneously complimenting its adoption of Open Access.

\section{Vertical Integration as Rent-Seeking}

While the vertical integration of Elsevier's products in the academic production cycle brings the potential for greater convenience, the products themselves build a clear dependency through its integration into the institutional workflow. Elsevier's further move to offering metrics-based decision making is simultaneously a move to gain further influence in the entirety of the university process, as well as to monetize its disproportionate ownership of content, in addition to cementing an increasing supply of content through such dependence. Here, Elsevier leverages the university's attempts to compete and promote to enhance their dependency upon the products. Especially as Open Access increasingly encroaches the rentiership capacity of Elsevier, this dependence allows Elsevier the dual capacity of extracting further value through the sale of data analytics as well as promote their existing content, both rent-seeking behavior.

Here, the sale of data exists on the monetization of already paid for/public information, an attempt to maximize the rent on the knowledge obtained as journal articles through the process of accumulation by dispossession (Zeller 2008). While the promotion of impact metrics as a measurement of journal article performance in conjunction with potential conflicts of interest in the lifecycle ownership may enable Elsevier to further protect and promote publication and citation of its core content. The promotion of impact metrics and high impact journals favors established titles within the collection of journals, titles which Elsevier and the other large publishers have had the time and capacity to acquire. While the promotion of publication within high impact journals further entrenches their status, with this attempt to generate dependency being especially an attempt to maximize rent, rent-seeking, rather than producing additional value.

41 Here it is important to note that the use of metrics has been encouraged not only by Elsevier but also by Wiley and Taylor Francis through their use of Altmetric within their online platforms (Watson 2016 and Taylor \& Francis n.d.). This is combined with the potential for conflicts of interest to exist within Scopus (Elsevier 2018b) search results or the curation of titles for SSRN whereby there is the potential for internal direction to 
favour Elsevier: a casualty of the proprietary algorithmic nature of search engines functions as reflected in the antitrust google search result manipulation case (Lee 2017). Thus vertical integration and the promotion of citation metrics may, in fact, constitute rent-seeking behavior designed to increase the dependency of products, further monetize content ownership, and entrench established journals.

Finally, this form of rent-seeking behavior is noted to play complement to the more traditional conceptions of rent-seeking as an enhancement of Intellectual Property Rights (as described by Zeller 2007). Rather, it is with vertical-integration and the promotion of metrics, as a quantification of reputability, that publishers are able to co-opt and monetize Open Access to a greatest extent, with the move towards infrastructure and Open Access thus being simultaneous and complementary processes.

\section{Exclusionary Implications towards Global South Journals and Researchers}

The implications of a dependency towards the products of publishers such as Elsevier as well as the promotion of citations metrics have the potential negative external implication of furthering inequalities through the exclusion of global south journals and researchers. Products such as SciVal, Mendeley, and SSRN promote collaborations within their potential paying customers. While the matching features of the Elsevier Fingerprint Engine is limited to English, further excluding non-english using global south researchers from a technology that Elsevier is increasingly adopting. Furthermore, the funding targeting abilities and comprehensive databases within products such as SciVal Funding can potentially increase the difficulty of Global South researchers in acquiring funding, due to their lack of optimization. Finally, the promotion of citation metrics favours Global North journals, who have benefited from the western modality of research as well as the western focus of existing scholarship, to the potential exclusion of global south scholarship. Here, for the global south scholarship to join the discourse and participate, there exists an increasing need to adapt to the western forms of scholarship and an increasing allure for global south journals in joining a global north publisher. Joining a global north publisher, in particular, serves as a form of academic neocolonialism, as the global north firm will have a direct influence upon the policies of such journals; while the adoption of western forms of scholarship merely enhances the hegemonic effect of global north academia. Both processes thus add new layers of marginality to global southern epistemologies. Such is only a precursory discussion of the potential exclusionary implication.

\section{Conclusions}

Having corroborated the historical increase in concentration within the academic publishing industry through the methodology of mergers and acquisitions, we further described the potential shift of publishers towards associated academic services/data analytics as a simultaneous process to the embracement of open access, their clear intent to leverage their disproportionate content ownership. We have showcased the clear strategic intent of both RELX and Wiley in diversification. We believe in particular that the differing expansion paths for the two companies may be a form of oligopolistic 
behavior to not only leverage competencies but also enhance monopoly power within each lifecycle, whether being education or academic production.

Wiley attempts to make its services increasing compulsory through its vertical integration of the education process, generating dependency in cost savings and in their education consulting. Especially as online programs become more prevalent, the dependency upon services such as Wiley's becomes increasingly entrenched; while corresponding to it is an increasing ceding of control from the institution to Wiley, as Wiley increasingly embeds itself into the process. Wiley's transformation into an Education Services provider is thus an interesting source of potential future research.

The vertical integration of Elsevier products within the Academic Knowledge Production Lifecycle generates an increasing dependency upon Elsevier products not only through the convenience provided, but also its embedment within the university decision-making process. As universities increasingly feel the need to out-perform/keep up and thus choose to adopt Elsevier's services, control is ceded to Elsevier either indirectly through decision making utilizing Elsevier generated data, or directly with Elsevier's recommendations on funding/collaboration options. Here, Elsevier not only extracts rent through the ownership of data but also through the promotion of high impact journals with the increasing adoption of citation metrics, metrics being simultaneously promoted by publishers such as Wiley and Taylor Francis. We expect the exclusionary forces generated by the increasing adoption of Elsevier products to have a direct impact on the diversity of knowledge production, with exclusion on funding, citations/discourse, and collaboration, a recommended source of further research.

Thus despite the superficial benefits of the rising uptake of certain open access practices by big publishers, it is clear that they are developing alternative methods of entrenching dependency by institutions and individual researchers. This integration has the further potential to exert a direct exclusionary effect on less financially well-endowed journals and institutions, primarily those in the Global South, in their compulsion to adopt the western modality of knowledge production. To ensure the global resolutions of inequalities in discourse and scholarly representation there is thus a clear need for a community-driven integration of scholarly infrastructure, one that is aware of the potential of inequality preparation within the community rather than one which only seeks to add value and co-opt the process for the objective of rent.

\section{BIBLIOGRAPHY}

\section{References}

Altmetric. (2015, May 28). Altmetric in the News [Press release].Retrieved from https://

www.altmetric.com/press/press-releases/whos-talking-about-research-taylor-francis-groupadds-altmetric-to-their-journals-platform/ 
Andreucci, D. et al. (2017). “ 'Value Grabbing’: A Political Ecology of Rent.” Capitalism Nature Socialism. http://dx.doi.org/10.1080/10455752.2016.1278027

Bepress. (2017). Features. Retrieved from https://www.bepress.com/products/digital-commons/ features/

Bepress. (2017). Expert Gallery Suite. Retrieved from https://www.bepress.com/products/expertgallery-suite/

Bepress. (2017). Why Digital Commons. Retrieved from https://www.bepress.com/products/digitalcommons/why-digital-commons/

Bepress (2017). Impact and Analytics. Retrieved from https://www.bepress.com/impact-analytics/ Birch, K. (2017c). Financing technoscience: Finance, assetization and rentiership. In D. Tyfield, R., Code Ocean. (2018, January 30). Taking the journal article to the next level: Taylor \& Francis partner with Code Ocean [Press release]. Retrieved from https://codeocean.com/press-release/taking-the-journalarticle-to-the-next-level-taylor-francis-partner-with-code-ocean

Digital Science. (2012, June 21). Digital Science Announces Support for Altmetric, a Project That Tracks the Online Conversations About Research [Press release]. Retrieved from https://www.digitalscience.com/press-releases/digital-science-announces-support-for-altmetric-a-project-thattracks-the-online-conversations-about-research/

Digital Science. (2018). Our Portfolio. Retrieved from https://www.digital-science.com/products/

Elsevier. (2018). Features and Benefits. Retrieved from https://www.elsevier.com/solutions/ hivebench/features-and-benefits

Elsevier. (2018). Scopus. Retrieved from https://www.elsevier.com/solutions/scopus

Elsevier. (2018). SciVal Funding helps researchers, administrators and research development professionals find new funding opportunities. Retrieved from https://www.elsevier.com/solutions/scivalfunding/features

Elsevier. (2018). Find the perfect journal for your article. Retrieved from https:// journalfinder.elsevier.com/

Elsevier. (2018). Elsevier Fingerprint Engine. Retrieved from https://www.elsevier.com/solutions/ elsevier-fingerprint- engine

Elsevier. (2018). Features. Retrieved from https://www.elsevier.com/solutions/pure/features

Elsevier. (2018). See what SciVal can do for you. Retrieved from https://www.elsevier.com/ solutions/scival/features

Elsevier. (2018). Who uses Analytical Services. Retrieved from https://www.elsevier.com/solutions/ analytical-services/who-uses-analytical-services

Elsevier. (2018). Open access. Retrieved from https://www.elsevier.com/about/open-science/ open-access

Felli, R. (2014). “On climate rent”, Historical Materialism 22(3-4): 251-280.

Fuller, S. (2016). Academic Caesar, London: Sage.

Hall, M. (2010). “Minerva's owl. A response to John Houghton and Charles Oppenheim's 'The economic implications of alternative publishing models'," Prometheus: Critical Studies in Innovation 28(1): 61-71. 
Harvey, D. (2002). "The Art of Rent: Globalization, Monopoly and the Commodification of Culture," Socialist Register 38: 93-110.

Harvey, D. (1982[1999]). The Limits to Capital, London: Verso.

Informa. (2016). Balance and Breadth. Retrieved from http://fr.zone-secure.net/20307/320850/

publication/contents/templates/pdfs/

Informa_Annual_Report_and_Financial_Statements_2016.pdf

John Wiley and Sons. (2017, December 6). Wiley Reports Second Quarter 2018 Results [Press release]. Retrieved from http://newsroom.wiley.com/press-release/all-corporate-news/wiley-reportssecond-quarter-2018-results

John Wiley and Sons. (2011). FISCAL YEAR 2011 10-K. Retrieved from https://www.sec.gov/ Archives/edgar/data/107140/000010714011000016/fy11-10k.pdf

John Wiley and Sons. (2017). FISCAL YEAR 2017 10-K. Retrieved from https://s3.amazonaws.com/ wiley-ecomm-prod-content/April+30\%2C+2017.pdf

John Wiley \& Sons. (2018). Empowering students to go farther. Retrieved from https:// www.wileyplus.com/capabilities/

John Wiley \& Sons. (2018). Wiley Custom Select. Retrieved from https://customselect.wiley.com/ John Wiley \& Sons. (2018). Wiley Job Network. Retrieved from https://www.wileyjobnetwork.com/ Larivière, V., Haustein, S., \& Mongeon, P. (2015). “The Oligopoly of Academic Publishers in the Digital Era." Plos One, 10(6). https://doi.org/10.1371/journal.pone.0127502

Lee, T.J. (2017). Why the EU's massive antitrust fine could become a huge headache for Google. https:// www.vox.com/new-money/2017/6/27/15880098/google-eu-antitrust-fine

Mendeley. (2017). Get on top of your research. Retrieved from https://www.mendeley.com/ reference-management/reference-manager

Mendeley. (2017). Share and discover datasets. Retrieved from https://www.mendeley.com/ datasets

Mendeley. (2017). Join a community of over 6 million users. Retrieved from https:// www.mendeley.com/research-network/community

Mendeley. (2017). Pick a plan that's right for you. Retrieved from https://www.mendeley.com/ upgrade/storage/

Mendeley. (2017). Search 135,515 science and technology jobs on Mendeley Careers. Retrieved from https://www.mendeley.com/careers/

Mendeley. (2017). Connect to a world of research funding. Retrieved from https://

www.mendeley.com/funding

Plum analytics. (2018). PlumX Dashboards. Retrieved from. https://plumanalytics.com/integrate/ plumx-dashboards/

RELX. (2008). Reed Elsevier Annual Reports and Financial Statements 2007. Retrieved from https:// www.relx.com/ /media/Files/R/RELX-Group/documents/reports/annual-reports/2007-annualreport.pdf

Schonfeld, R.C. (2017). Elsevier Acquires bepress. Retrieved from https:// scholarlykitchen.sspnet.org/2017/08/02/elsevier-acquires-bepress/ 
Schwartz, H.M. (2017). "Club goods, intellectual property rights, and profitability in the information economy," Business and Politics 19(2): 191-214.

SSRN. (n.d). Create an Account. Retrieved from https://hq.ssrn.com/login/pubSignInJoin.cfm? link=2007-4th-PSED

SSRN. (n.d). Is SSRN Free? Retrieved from http://support.ssrn.com/knowledgebase.php?article=26

SSRN. (n.d). SSRN Top 10,000 Papers. Retrieved from https://hq.ssrn.com/rankings/

Ranking_display.cfm?TRN_gID $=10$

SSRN. (n.d). Current Subscribers. Retrieved from https://www.ssrn.com/en/index.cfm/subscribe/

Taylor \& Francis. (2017, May 30). Academic Digital Research Services start-up colwiz joins Taylor \& Francis Group [Press release]. Retrieved from http://newsroom.taylorandfrancisgroup.com/news/ press-release/academic-digital-research-services-start-up-colwiz-joins-taylor-francis

Taylor And Francis. (n.d.). Measuring impact with article metrics. Retrieved from https:// authorservices.taylorandfrancis.com/measuring-impact-with-article-metrics/

Ware, M. \& Mabe, M. (2015). The STM Report: An overview of scientific and scholarly journal publishing. Retrieved from https://digitalcommons.unl.edu/cgi/viewcontent.cgi?referer=https:// www.google.ca/\&httpsredir=1\&article=1008\&context=scholcom

Watson, R. (2016). The Importance of Altmetrics: A Primer. Retrieved from https://hub.wiley.com/ community/exchanges/discover/blog/2016/06/01/the-importance-of-altmetrics-a-primer

Wiley Education Services. (2018). Higher Education Services With Impact. Retrieved from https:// edservices.wiley.com/why-partner/services-and-solutions/

Wiley Education Services. (2017). While On-Ground Graduate Business Programs Remain Competitive, Abundant Opportunities Still Exist for Online Offerings. Retrieved from https://edservices.wiley.com/ mba-opportunities/

Zeller, C. (2008). "From the gene to the globe: Extracting rents based on intellectual property monopolies." Review of International Political Economy 15(1): 86-115.

\section{ABSTRACTS}

This paper attempts to illustrate the implications of a simultaneous redirection of the big publishers' business strategy towards open access business models and the acquisition of scholarly infrastructure utilizing the conceptual framework of rent-seeking theory. To document such a transformation, we utilized financial databases to analyze the mergers and acquisitions of the top publicly traded academic publishers. We then performed a service analysis to situate the acquisitions of publishers within the knowledge and education life-cycles, illustrating what we term to be their vertical integration within their respective expansion target life-cycles. Implications of higher education institutions' increased dependency towards the companies and increased influence by the companies on the institution and individual researcher were noted from the vertical integration of products. Said vertical integration is analyzed via a rent theory framework and described to be a form of rent-seeking complementary to the redirection of business strategies to open access. Finally, the vertical integration is noted to generate exclusionary effects upon researchers/institutions in the global south. 
INDEX

Keywords: knowledge production, rent-seeking, scholarly infrastructure, concentration, inequality

\section{AUTHORS}

\section{ALEJANDRO POSADA}

Knowledge GAP, Colombia

alejandroposada71@gmail.com

(corresponding author)

\section{GEORGE CHEN}

Knowledge GAP-University of Toronto, Canada

zhiwen.chen@mail.utoronto.ca 